\title{
Transformaciones conceptuales del paisaje urbano de Medellín
}

\author{
Olgalicia Palmett Plata ${ }^{1}$, olgalicia.palmett@colmayor.edu.co
}

\begin{abstract}
RESUMEN
El acelerado y muchas veces poco previsto crecimiento urbano transforma los elementos cotidianos de habitabilidad, pues no sólo altera lo más sensible del orden natural, sino que impone nuevas formas de construir la ciudad y nuevos usos del espacio contemporáneo, mediante la relación establecida con conceptos como lo efímero, lo nómada, las mutaciones, las hibridaciones, los nichos urbanos y las redes, lo que genera una multitud de formas de ocupar y habitar la ciudad. El aporte de este trabajo es la identificación de factores que favorecen las acciones de impermanencia que dan lugar a transformaciones conceptuales del paisaje urbano de Medellín, leyendo en sus paisajes urbanos pasados, en contraste con los actuales, los patrones de ocupación dominantes que dan lugar a nuevos espacios habitables. Todo lo anterior se logra a partir del análisis perceptual del paisaje urbano por medio de la mirada común de los habitantes que experimentan el estar, el soñar, el imaginar y son ellos finalmente los que establecen los nuevos flujos, movimientos y posibilidades de habitarlo, dando como resultado una ciudad con características intangibles y hasta poco visibles, en constante transformación.
\end{abstract}

Palabras clave: ciudad, Medellín, paisaje urbano, transformaciones conceptuales.

\section{Conceptual transformations cityscape Medellín}

\begin{abstract}
Accelerating urbanization, which is often poorly planned, transforms the everyday elements of habitability, because it not only alters the natural order, but also imposes new ways to build the city and new uses of contemporary space, through the relationship established with concepts such as ephemeral, nomadic, mutations, hybridizations, urban niches and networks, creating a multitude of ways to occupy and inhabit the city. The contributions of this paper are the identification of factors that favoring impermanent actions that lead to conceptual changes in the urban landscape of Medellín, reading its previous urban landscapes in contrast with the current, dominant patterns of occupation, which have resulted in new living spaces. All this is achieved from the perceptual analysis of the urban landscape through the eyes of the common people who experience the room, dreaming, imagining and they are finally establishing new flows, movements and possibilities to inhabit, resulting in a city with intangible characteristics, which are often inconspicuous and constantly changing.
\end{abstract}

Keywords: city, Medellin, cityscape, conceptual transformations.

Recibido el 12 de junio de 2015, aceptado el 30 de noviembre de 2015.

1 Grupo de Investigación Ambiente, Hábitat y Sostenibilidad. Facultad de Arquitectura e Ingeniería. Institución Universitaria Colegio Mayor de Antioquia. Carrera 78 \# 65 - 46, Medellín, Antioquia, Colombia. 


\section{INTRODUCCIÓN}

Este trabajo ofrece una reflexión sobre la manera cómo la ciudad de Medellín, Colombia, se ha transformado a partir de las distintas formas de habitar el territorio, lo que ha dado lugar a diversos tipos de ciudad, tipos de ciudadanos y formas distintas de vivir en una ciudad dinámica $y$ en constante cambio, no necesariamente para evolucionar en el hecho, mas sí para fortalecerse y emerger de los embates del desarrollo.

Las formas de habitar y construir el territorio emergente de acciones de impermanencia generan transformaciones territoriales urbanas. Nuevos territorios, invisibles, intangibles, pero reales. Un paisaje urbano en constante cambio.

La ciudad es un espacio geográfico, por tanto, territorio, escenario o hábitat que acoge las actividades públicas y privadas, donde se desarrollan las funciones de residencia, gobierno, transformación e intercambio, es decir, la vida de los habitantes. "El paisaje natural subyace a la ciudad. El paisaje natural es estructura y soporte del paisaje urbano" (MONTOYA VALENCIA 2011: 1).

El paisaje urbano, instalado en el espacio urbano, tiene una serie de características que lo diferencian del paisaje de otros espacios: por un lado, se destaca por la alta densidad de población que vive en el mismo; y por otro, suele tener una gran heterogeneidad en cuanto a su extensión y una arquitectura en sus edificios que resulta inconfundible.

Reflexionar sobre cómo Medellín se ha transformado implica establecer algunos propósitos de investigación:

a) Registrar gráficamente las nuevas formas de construir la ciudad y el espacio contemporáneo, a través de la relación establecida con conceptos como lo efímero, lo nómada, las mutaciones, las hibridaciones, los nichos urbanos y las redes urbanas, que generan una multitud de formas de ocupar y habitar el paisaje urbano; b) caracterizar las formas de ocupar y habitar el paisaje urbano, por cada uno de los conceptos ya señalados, en la construcción de la ciudad y el espacio urbano contemporáneo; c) identificar los factores que favorecen las acciones de impermanencia del habitante en la ciudad en relación con los conceptos escogidos, para definir los patrones de ocupación dominante que dan lugar a nuevos espacios; d) detectar la tendencia urbanística que imponen los conceptos de lo efímero, lo nómada, las mutaciones, las hibridaciones, los nichos urbanos y las redes urbanas, en las nuevas maneras de habitar y ocupar el paisaje urbano.

\section{MATERIALES Y MÉTODOS}

El estudio se llevó a cabo a partir de la dinámica de investigación descriptiva, cuyo objetivo es registrar gráficamente la relación que se establece con los conceptos de lo efímero, lo nómada, las mutaciones, las hibridaciones, los nidos urbanos y las redes urbanas, con las nuevas formas de habitar y construir la ciudad, a partir de la estrategia de investigación de estudio de casos, para lo cual se ha escogido la ciudad de Medellín.

Para emprender la indagación en esta investigación y poder describir las distintas transformaciones fue preciso realizar un análisis perceptual del paisaje urbano e incluir a los habitantes de los lugares escogidos de Medellín, considerados significativos para el estudio por su importancia social y espacial. Se realizó la recolección de los datos a partir de la observación y la mirada común del que experimenta el estar, el soñar, el imaginar y el descubrir nuevos flujos, movimientos y posibilidades de habitarlo, tal como señala GUBER (2001:56) en la investigación etnográfica: "La aplicación de esta técnica, 
o mejor dicho conceptualizar actividades tan disímiles como 'una técnica' para obtener información, supone la presencia (la percepción y las experiencias directas) ante los hechos de la vida cotidiana de la población, que garantiza la confiabilidad de los datos recogidos y el aprendizaje de los sentidos que subyacen a dichas actividades". Se realizó el análisis a través de la fotografía y entrevistas informales a habitantes de los sectores escogidos, no importando la edad, el género, la actividad o el estrato socioeconómico.

Para el análisis de los datos se consideraron aspectos cualitativos y cuantitativos, llevando a cabo una recolección de datos con los siguientes procedimientos:

- Pesquisas de documentos territoriales específicos del contexto de estudio: ciudad de Medellín.

- Análisis de contenidos cartográficos de mapas, planos e imágenes, a partir de la clasificación, contrastación y categorización de la información hallada en cada instrumento (imágenes, planos, mapas).

- Rastreo bibliográfico general sobre los conceptos de análisis (lo efímero, lo nómada, las mutaciones, las hibridaciones, los nichos urbanos y las redes).

Las actividades que determinaron el procesamiento y análisis de los datos fueron:

- Descripción y localización de las diferentes unidades paisajísticas, es decir los lugares significativos de la ciudad de Medellín, tales como riberas del Río Medellín, centro de la ciudad, barrios marginados y periurbanos.
- Análisis del paisaje: evaluación de la calidad visual del paisaje, de las diferentes unidades paisajísticas escogidas.

- Identificación de las actuaciones con impactos paisajísticos para su descripción, clasificación y análisis en relación con los conceptos de lo efímero, lo nómada, las mutaciones, las hibridaciones, los nidos urbanos y las redes urbanas.

\section{Paisaje urbano y unidades de paisaje}

Como paisaje urbano de Medellín se escogieron lugares significativos para la investigación, que son sectores que presentan gran contraste social y que culturalmente marcan un interés, ya sea por el escaso patrón en el uso del suelo o las manifestaciones de cambio cultural que se originan allí; se han denominado unidades paisajísticas el centro de la ciudad, las riberas del Río Medellín y los barrios marginados y periurbanos, de acuerdo a las siguientes particularidades:

\section{Unidad de paisaje: centro de Medellín}

En el centro de Medellín se tuvo en cuenta aquella zona comprendida por los barrios tradicionales, como son (1) Prado, (2) Estación Villa, (3) San Benito, (4) Guayaquil, (5) Corazón de Jesús, (6) Colón, (7) Bomboná No. 1, (8) Boston, (9) Los Ángeles, (10) Villanueva y (11) La Candelaria (Fig. 1).

\section{Unidad de paisaje: ribera del Río Medellín}

La ribera del Río Medellín o Aburrá es la zona comprendida como la cuenca hidrográfica del río en área urbana, entre Bello e Itagüí (Fig. 2). 


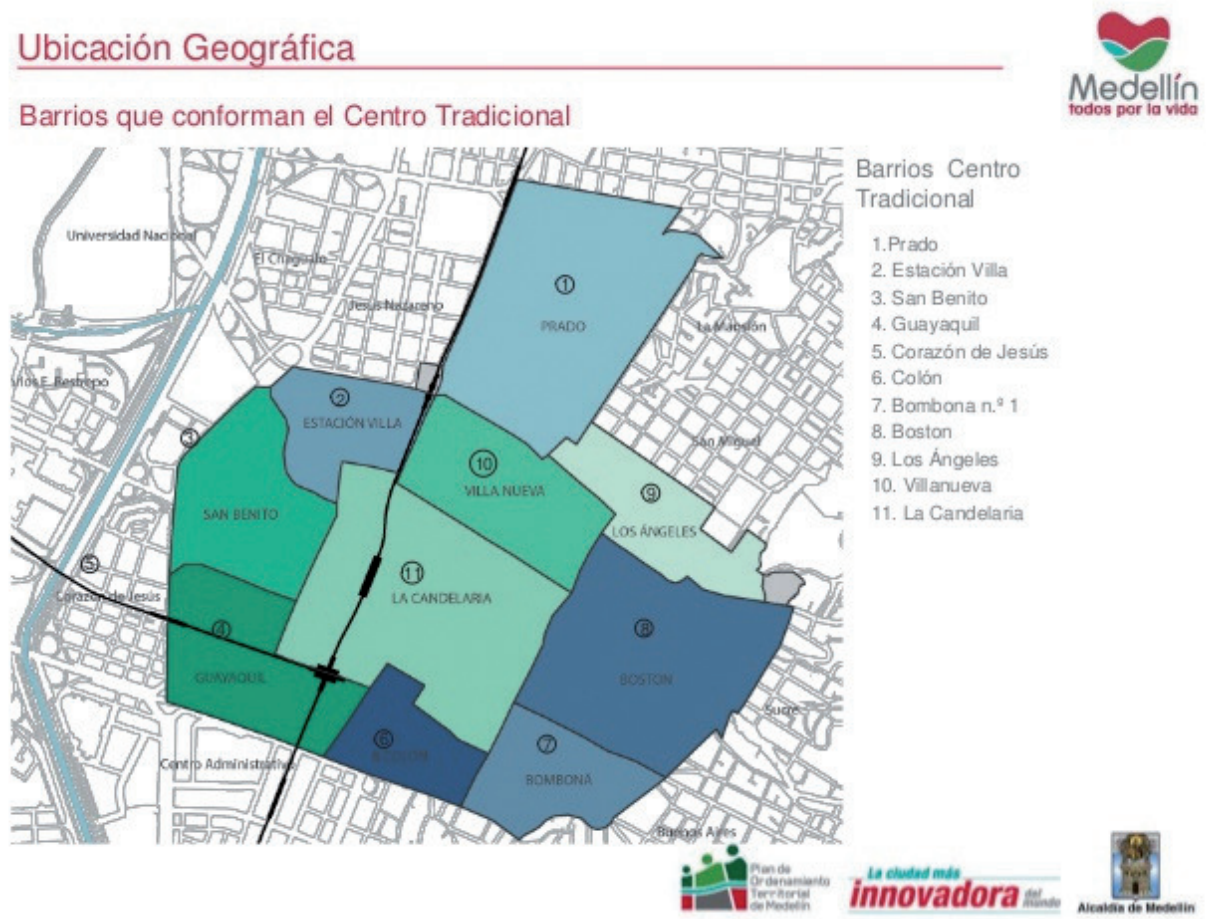

Fig. 1. Centro Tradicional de Medellín.

Fig. 1. Traditional Medellín downtown.

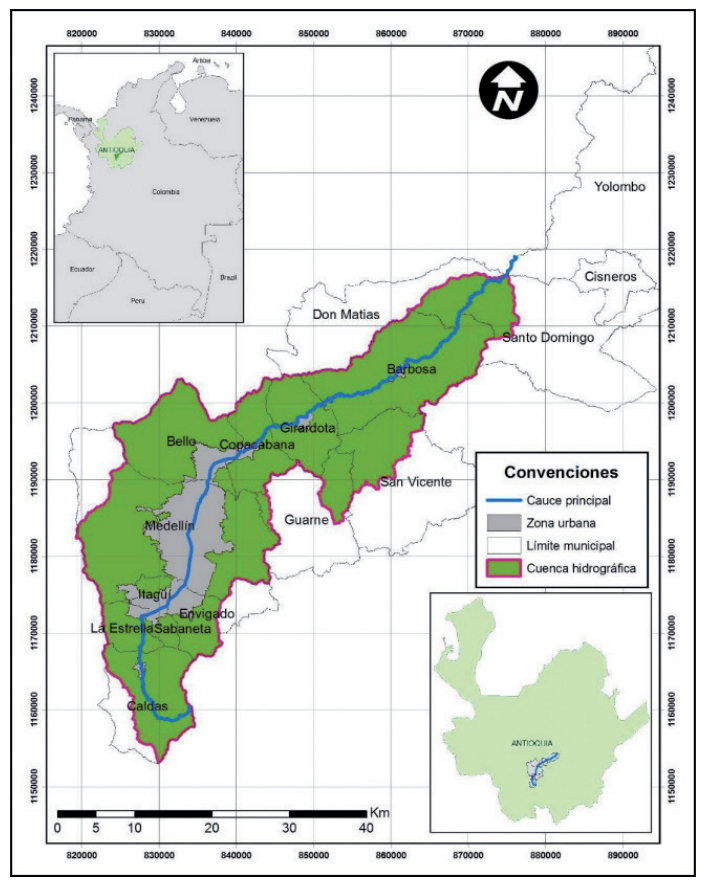

Fig. 2. Cuenca hidrográfica del Río Medellín en área urbana entre Bello (Norte) e Itagüí (Sur). Fuente: Montoya \& Vázquez, en: udea.edu.co

Fig. 2. Medellín River Watershed in urban area between Bello (North) and Itagüí (South). Source: Montoya \& VÁzquez, in: Udea.edu.co 


\section{Unidad de paisaje: periferias urbanas}

Como periferias urbanas se contemplaron los asentamientos informales y los sectores deprimidos en la frontera urbana, marcados en color rojo en la Figura 3. Tales asentamientos han tenido una posición geográfica hacia los sectores noroccidental y nororiental.

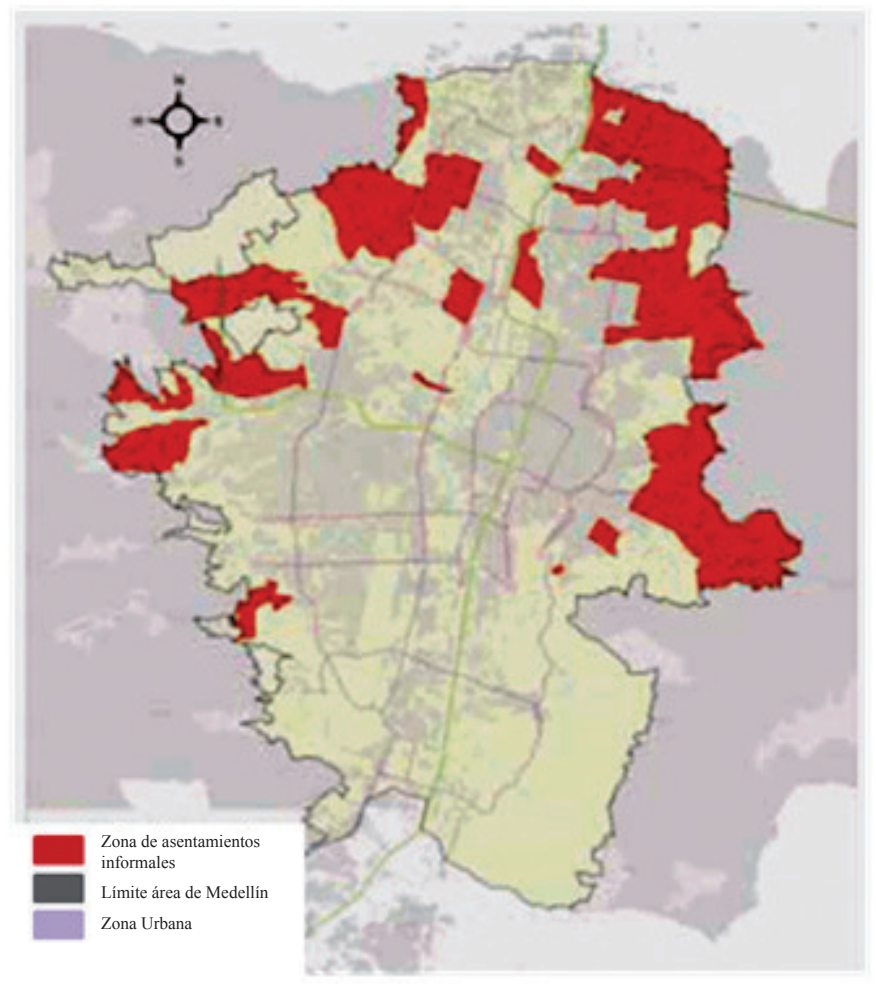

Fig. 3. Zonas de asentamientos informales. Fuente: Dávila et al. (2006).

Fig. 3. Areas of informal settlements. Source: Dávila et al. (2006).

\section{RESULTADOS}

Factores que favorecen las acciones de impermanencia

Realizado el análisis perceptual de las unidades de paisaje, la característica encontrada en su cotidianidad es la movilidad, la inconstancia y la impermanencia de sus habitantes. Esta última es un principio hallado en muchos aspectos de la vida misma y ha sido estudiado desde la antigüedad por científicos como el naturalista Charles Darwin, quien afirma que la vida está en constante movimiento y evolución, y por filósofos budistas que han adoptado este principio como el fundamento espiritual de todo ser vivo. Todo lo que rodea al ser humano está predestinado a cambiar $\mathrm{y} / \mathrm{o}$ a transformarse por efecto del tiempo y las circunstancias (Heráclito). Esta es una de las leyes universales, la ley del ritmo o de impermanencia de todas las cosas (TRISMEGISTO 2012: 13).

La impermanencia, más allá de la no existencia, es considerada un fenómeno que cubre la transformación momento a momento y que es motivada por varias circunstancias en la vida del hombre. La impermanencia es constante transformación, por tal motivo se asocian a ella ciertas 
acciones del hombre producto de su afán de mejores condiciones de vida, mejores oportunidades, pertenencia y arraigo. Pero, ¿cuáles son esos factores que favorecen y promueven las acciones de impermanencia y que imponen lo transitorio en la vida del hombre de ciudad?

Los elementos o circunstancias que contribuyen a la impermanencia de los ciudadanos dentro de la ciudad son la pobreza, la violencia y el conflicto armado, el desplazamiento y la marginalidad social. Estos factores promueven y aceleran la impermanencia de los grupos humanos en las distintas unidades de paisaje de la ciudad de Medellín escogidos para este estudio.

\section{La pobreza}

La COMISIÓN ECONÓMICA PARA AMÉRICA LATINA Y EL CARIBE (CEPAL) establece los determinantes de la pobreza en Colombia, en donde, gracias a una metodología de descomposición, se establecen las características de la evolución de la pobreza en la década de los noventa, el aumento de la población, las características de los hogares pobres y sobre todo se exponen cuáles son los efectos básicos de las variables macroeconómicas sobre el nivel de pobreza. Basados en este informe y en consonancia con otros de la misma índole expuestos por otros autores, se asume la pobreza como un factor o circunstancia que promueve la impermanencia de algunos habitantes de la ciudad.

La pobreza es considerada la carencia o escasez de recursos necesarios para satisfacer las necesidades básicas de una población o grupo de personas específico. No se puede definir de forma general para todas las regiones o territorios, ya que ésta depende de patrones culturales que determinan el estilo de vida imperante en cada región o lugar.

Según estudios del BANCO MUNDIAL (2015), EL BANCO INTERAMERICANO
DE DESARROLLO (1998), existen dos clases de pobreza: la absoluta y la relativa. La pobreza absoluta es aquella que no cubre el cumplimiento de la canasta de consumo mínima, entendiendo como canasta de consumo mínima aquella que incluye alimentación, vivienda, salud, vestido y otros. La pobreza relativa es aquella que no se mide a partir de la ausencia total de cubrimiento de las necesidades básicas, sino que en ella se logran cubrir algunas de las necesidades de manera precaria y en algunos casos suficiente.

Lo anterior describe la pobreza desde el punto de vista teórico. Sin embargo, la realidad de la pobreza en la ciudad de Medellín es más compleja, ya que las condiciones de pobreza se manifiestan de forma muy variada, pero ninguna de ellas de manera agradable, por tal motivo las personas padecen la pobreza en su estado de permanencia, aquel impuesto por la sociedad y la cultura, del cual es muy complejo salir. Debido a que no son bien vistos en sectores acomodados de la ciudad, los pobres son relegados, ignorados y rechazados, lo que los lleva a buscar lugares más amables para su condición de vida. En consecuencia, la pobreza como estado económico cuasi-permanente genera situaciones de impermanencia espacial social y cultural.

\section{La violencia y el conflicto armado}

El concepto de violencia en Colombia debe ser visto desde diferentes perspectivas, pues ella surge como resultado de varias acciones emprendidas por grupos insurgentes, autodefensas, sicariato e inseguridad social. Lo que sí es constante es que hace referencia a actos de fuerza contrarios al derecho o a la ley y que llevan implícito el abuso del poder, la coacción y el uso de armas (CENTRO NACIONAL DE MEMORIA HISTÓRICA 2013: 111).

El conflicto armado en Colombia tiene su origen en la época de la violencia y ha 
tenido como actores principales al Estado colombiano, la guerrilla de extrema izquierda y los grupos paramilitares de extrema derecha. En la década de los años 80 , el narcotráfico entra a la dinámica del conflicto armado, como medio de financiación de algunos de los anteriores grupos. Las causas de su presencia y extensión en el tiempo se centran en la posesión de la tierra, las diferencias económicas y la persecución de la población civil debido a su orientación política. El conflicto armado ha obligado a miles de personas a desplazarse a las grandes ciudades de Colombia como Medellín. Es así como un factor de impermanencia como es el conflicto armado da lugar a otro factor de impermanencia como el desplazamiento.

\section{El desplazamiento}

Es la acción de movilidad forzada de comunidades campesinas, indígenas $\mathrm{y}$ afro-descendientes, a causa del conflicto armado interno en Colombia (NARANJO GIRALDO 2001). La población desplazada proveniente de otras ciudades de Colombia afecta de manera alarmante las cifras de habitantes en Medellín, trayendo como consecuencias el aumento en los niveles de desempleo, mayor pobreza y localidades marginales.

\section{La marginalidad social}

Lapoblación que llega a la ciudad de Medellín en calidad de desplazada engrosa la lista de pobreza, y la mayoría de estas personas se convierten en recicladores, vendedores ambulantes, sicarios, ladrones, estafadores, prostitutas e indigentes, es decir, son los llamados creadores de la cultura popular. Los lugares escogidos para establecerse generalmente son sitios de ladera y en la periferia de la ciudad, que son ilegales y de alto riesgo para sus vidas, generando lo que se conoce como asentamientos informales. "De acuerdo a la definición operativa de ONU-HÁBITAT (2003), un asentamiento informal se caracteriza por presentar una o más de las siguientes condiciones: hacinamiento crítico, estado precario de la vivienda (en relación a su estructura física y a su entorno), ausencia de algunos de los servicios públicos e ilegalidad de la tenencia" (ECHEVERRI \& ORSINI 2010: 130).

La calidad de vida de todas estas personas desplazadas adquiere una connotación de marginación o aislamiento, ya que se encuentran lejos de la colectividad y de las normas sociales comúnmente establecidas.

\section{Transformaciones conceptuales del paisaje urbano que imponen los factores de impermanencia}

La ciudad nació como lugar para los hombres sedentarios, pero hoy está más cercana al concepto de viaje que al de estación, más cercana al hombre nómada que al sedentario. Sin embargo, el hombre no descansa hasta encontrar su espacio para asentarse de forma definitiva.

La ciudad es hoy un contexto de ciudadanías diferentes, nómadas y desarraigadas, de multiplicidad cultural y simultaneidad, cada día más desligada de cualquier espacio formal; son comunidades creadas de acuerdo a sus tradiciones, raíces y ancestros; ciudades dinámicas atrapadas en un tiempo pasado mezclado con un tiempo actual.

Las diferentes transformaciones de la ciudad que a continuación se exponen no son estipuladas de manera general y concluyente, y de ellas no se ha hablado ni escrito ampliamente, debido a que se enmarcan en transformaciones conceptuales Son transformaciones que se han ido gestando desde los cambios que ha traído la contemporaneidad y que aún se encuentran en desarrollo, que aún no se han definido de manera completa, porque todavía siguen en transformación. Se abre así un panorama poco explorado en la clasificación de las transformaciones de la ciudad y en la inclusión de los conceptos de lo efímero, lo 
nómada, las mutaciones, las hibridaciones, los nichos urbanos y las redes.

Al exponer a continuación estas tipologías de ciudad y sus caracterizaciones, se busca reforzar la asociación de conceptos específicos con el ámbito urbano, habitacional, arquitectónico, social, cultural y económico, ya que son términos poco relacionados con las transformaciones de la ciudad, y por lo tanto, escasamente abordados de manera formal y prospectar las posibilidades que brindan dichos conceptos en las caracterizaciones que las transformaciones de la ciudad imponen al paisaje urbano. Cada una de las tipologías de ciudad expuestas a continuación no se presentan de manera exclusiva o única en una ciudad o en Medellín, si no que son tipologías implícitas en la ciudad y que se encuentran por lo general de forma conjunta, alguna de ellas en mayor o menor grado, haciendo parte de la ciudad en su caracterización total.

\section{Ciudad nómada}

El modo de vida de un número cada vez más significativo de ciudadanos se basa en un continuo traslado, sin residir de manera estable en algún lugar. La movilidad, el desarraigo y la inestabilidad son los sustantivos que rigen sus vidas y las formas urbanas de la ciudad nómada. De cerca, la ciudad enorme se visualiza fragmentada y dispersa.

"La ciudad nómada se corresponde con una arquitectura cuya clave es la flexibilidad, con formas que tienden a lo incompleto, a lo abierto, a lo no jerarquizado, a la fusión con el exterior, al desmantelamiento de los límites interno-externo, al amalgamamiento de elementos simples..." Los materiales que acompañan al discurso arquitectónico de la ciudad nómada son a menudo intercambiables o incluso desechables (ATRIBUTOS URBANOS 2006: 1).

Según PÉRGOLIS (2000: 5), "la ciudad nómada encierra, en la inestabilidad de sus manifestaciones nocturnas, una estética imposible porque ciudad y nómada siempre fueron palabras antagónicas; pero también podría afirmar que es una estética de la libertad, cuando toda la ciudad deviene casa para los habitantes de la noche".

La ciudad nómada la conforman los pobladores nómadas. Los transitorios o transeúntes de la ciudad, habitan sus lugares por momentos, no echan raíces en ninguna parte, como el caso de los asentamientos informales y los habitantes de la ribera del río. Lugares con pobladores cambiantes y asentamientos móviles.

\section{Ciudad mutante}

La ciudad padece transformaciones impuestas por la vulnerabilidad asociada a la presencia de zonas de riesgo. Estas zonas aumentan su vulnerabilidad al ser sometidas a situaciones extremas de sobrepoblación, construcción indebida o ubicación inconveniente de los asentamientos. Los fenómenos de origen natural, como lluvias extremas y vientos, generan situaciones de emergencia en zonas de ladera, ribera del río y suelos inestables, donde se producen deslizamientos e inundaciones fluviales, afectando en gran medida a los pobladores nómadas. Situaciones de desastre que imponen de manera transitoria un nuevo tipo de ciudad, la ciudad mutante. Algunos de los sectores estudiados (figuras 4 y 5 ) presentan hoy una apariencia diferente, debido a los cambios generados por eventos de riesgo natural. 


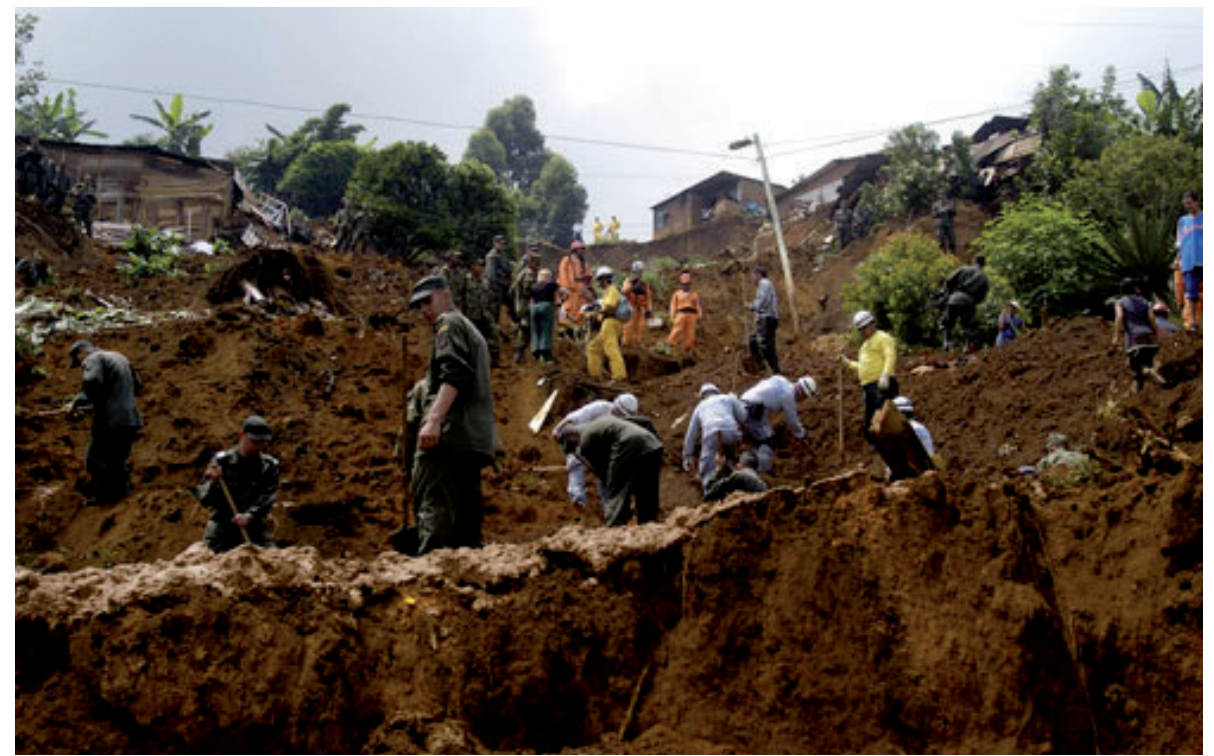

Fig. 4. Deslizamiento de tierras en el barrio La Cruz, Comuna 3. Cinco niños y tres adultos FALLECIERON Y 15 VIVIENDAS DESAPARECIERON EN LA TRAGEDIA OCURRIDA EN ESTE BARRIO DE Desplazados. Fuente: WWW.SURIMAGES.COM.

Fig. 4. Landslide in the La Cruz neighborhood in Comuna 3 district. Five Children and three ADULTS DIED AND 15 HOUSES WERE DESTROYED IN THE TRAGEDY IN THIS NEIGHBORHOOD OF DISPLACED. SOURCE: WWW.SURIMAGES.COM.

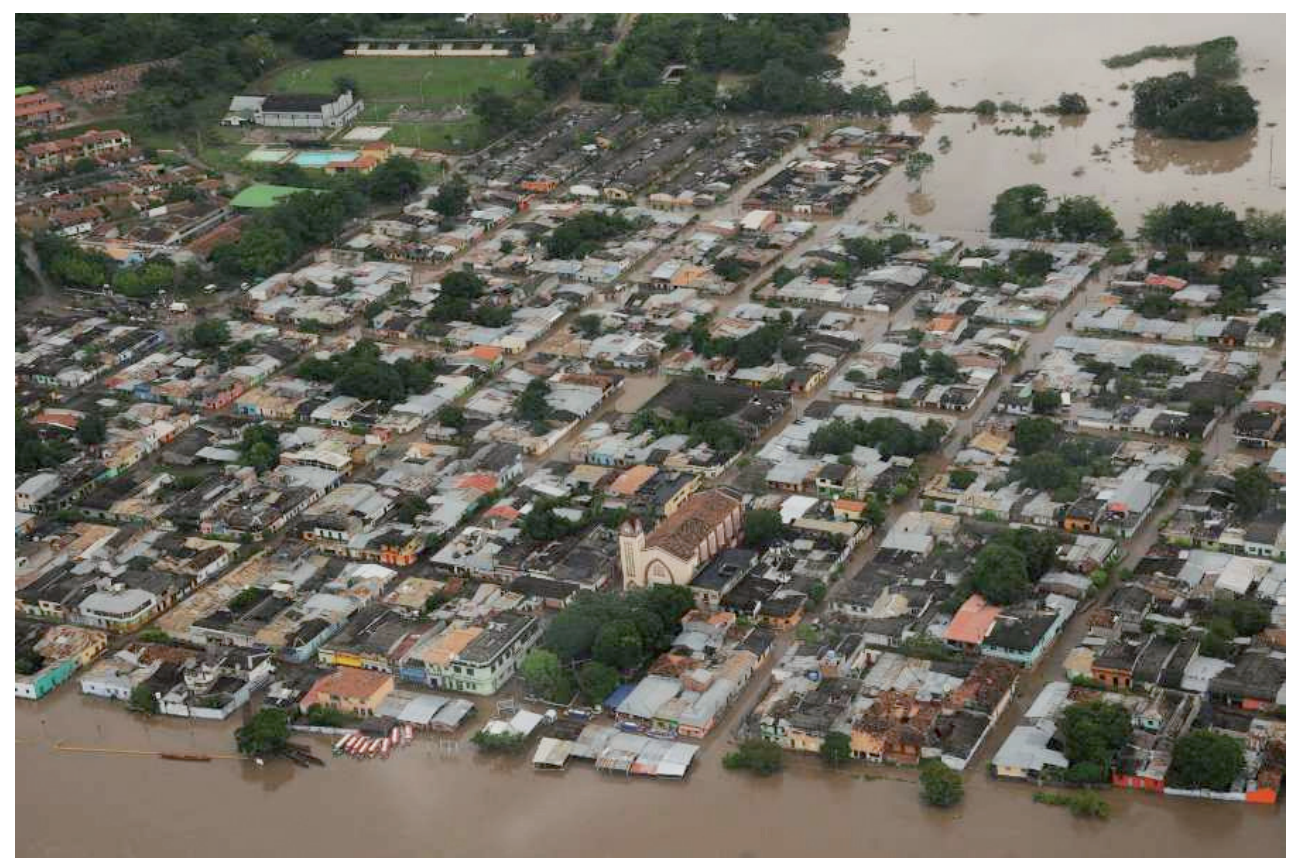

Fig. 5. Municipio de Puerto Nare inundado por la lluvia, Departamento de Antioquia. FUENTE: HTTPS://ARTESAVIA.FILES.WORDPRESS.COM/2011/11/INVIERNO.JPG

Fig. 5. Municipality of Puerto Nare flooded by rain, Antioquia Department. SOURCES: HTTPS://ARTESAVIA.FILES.WORDPRESS.COM/2011/11/INVIERNO.JPG 


\section{Ciudad de hibridaciones}

La desigualdad de recursos, de oportunidades y de calidad de vida entre miembros de una misma población es un fenómeno que caracteriza a la mayoría de las sociedades contemporáneas y su intensidad es tal, que empapa la forma de vestir, los estilos de vida y los espacios físicos. El contraste entre fragmentos urbanos, verdes y de concreto, riqueza y pobreza se hacen visibles en la ciudad híbrida, siendo única, inigualable y particular, pero no por eso la mejor vista de la ciudad. Medellín indiscutiblemente es una ciudad de contrastes, en donde la hibridación se hace presente permanentemente con la forma de habitar los espacios y de mostrar sus avances arquitectónicos y tecnológicos. Para graficar esta situación, un buen ejemplo lo constituye el Parque Biblioteca España, obra de Giancarlo Mazzanti, construcción contemporánea con estudios experimentales en sostenibilidad bioclimática y ecológica, ubicada en uno de los barrios más críticos económica y socialmente de Medellín. El contraste de la opulencia arquitectónica y constructiva se magnifica ante un fondo de casas diminutas, escalonadas sobre la montaña (Fig. 6).

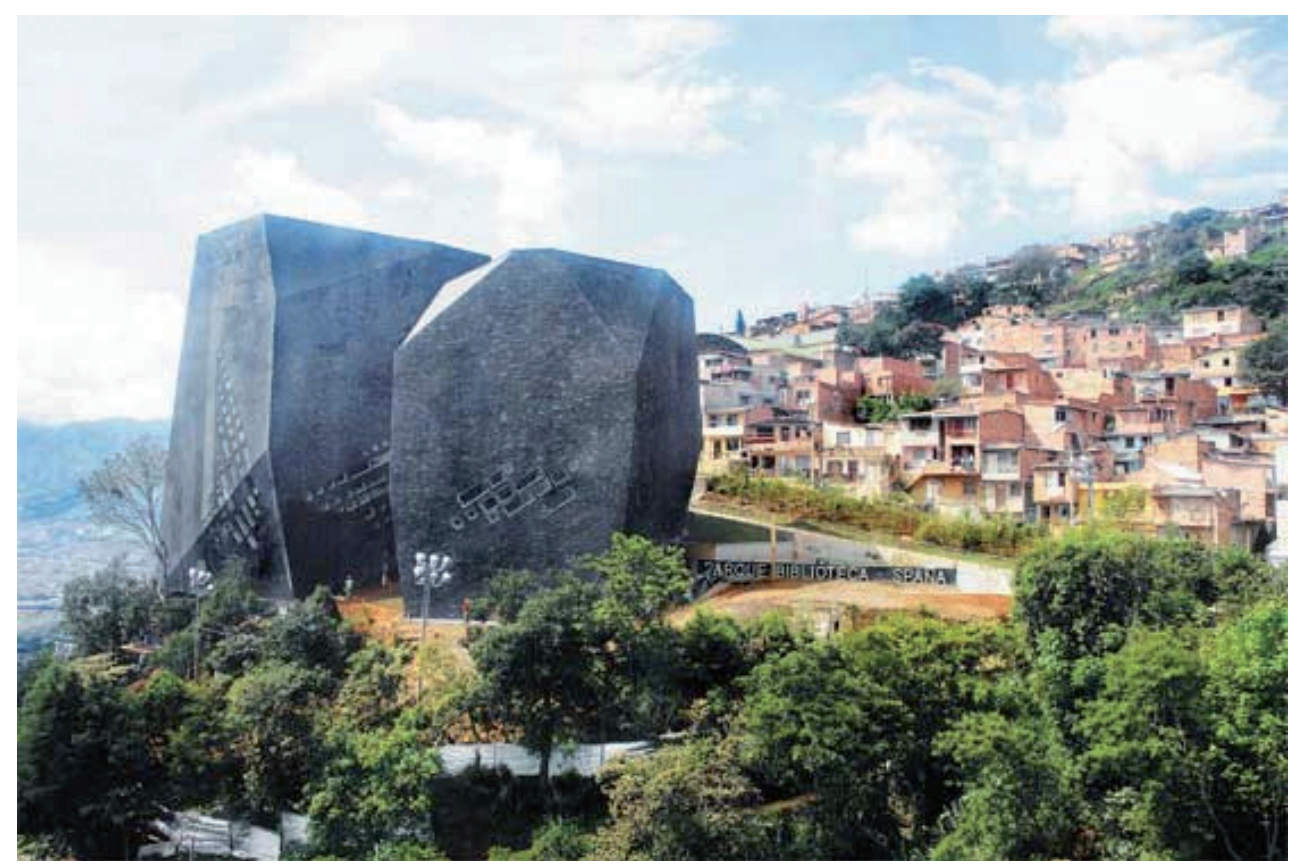

Fig. 6. Parque Biblioteca España, Medellín. Fuente: http://esferapublica.org/

Fig. 6. Spain Park Library, Medellín. Source: htTp://esferapublica.org/

Otro ejemplo corresponde a las líneas de Metrocable (teleféricos), Línea J y Línea K, ambas de cercanías urbanas que se conectan directamente con el sistema de trenes de la ciudad. A su vez, la Línea L conecta a los residentes de Parque Arvi, un gran parque situado a las afueras de Medellín. Uno de los medios de transporte más modernos con los que cuenta el sistema de transporte metropolitano a nivel latinoamericano, se eleva sobre casas con techo de zinc (Fig.7), siendo estos contrastes los que caracterizan a la ciudad de hibridaciones. El contraste se presenta enmarcado en la opulencia tecnológica del medio de transporte y la precariedad habitacional del paisaje urbano que tiene como fondo. 


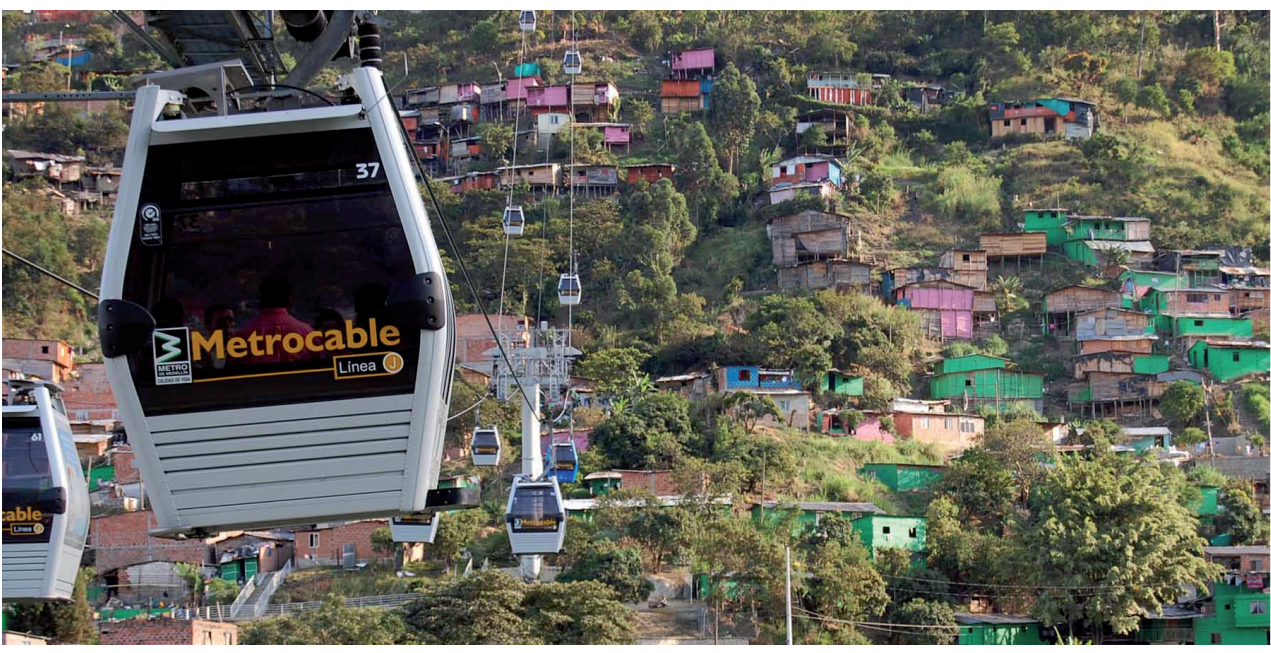

Fig. 7. Metrocable (teleférico) de Medellín. Fuente: hTtP:/WwW.inteligenciascolectivas. ORG/IC/WP-CONTENT/UPLOADS/2011/01/027.JPG

Fig. 7. Metrocable (Cable Car) Medellín. Source: hTtp://Www.inteligenciascolectivas.org/ IC/WP-CONTENT/UPLOADS/2011/01/027.JPG

\section{Ciudad efimera}

Ciudad efímera es aquella que transcurre con la cotidianidad, imperceptible pero real, presente pero poco reconocida. El estado efímero se presenta día a día de forma breve y pasajera, y aunque permite la experimentación de la ciudad, su duración temporal pero imponente crea impacto, novedad y da la sensación de mayor duración, de mayor permanencia por los imaginarios que crea en sus habitantes. Es el caso de la mirada que se puede realizar de la ciudad de día y de noche. Ciudad efímera entre el día y la noche (Fig. 8). La ciudad contenedora que nace con el día y se vacía de noche, dejando sólo su epidermis impermeabilizada como única opción de uso.
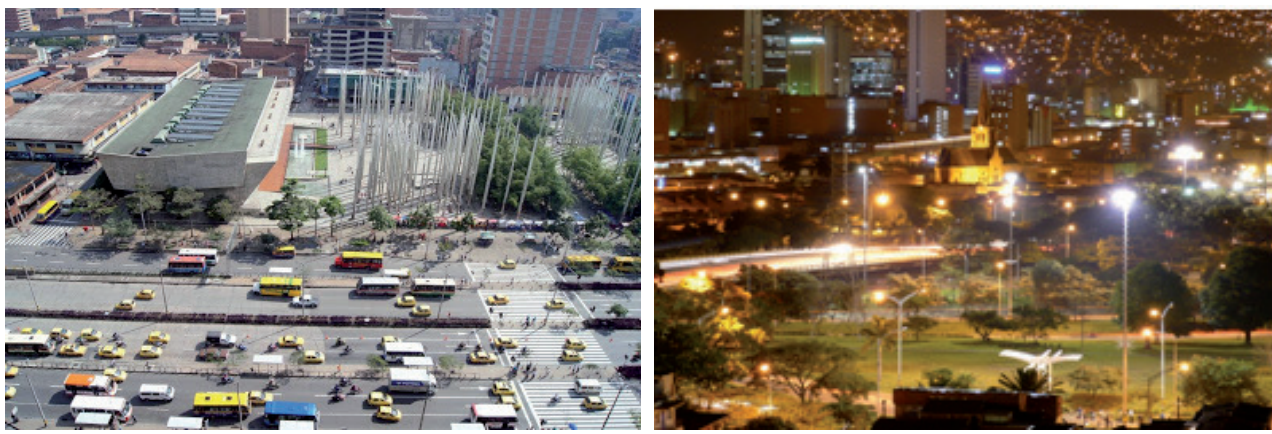

Fig. 8. Medellín de día y Medellín de noche. Fuente-a: http://par-lando.blogspot. COM/2011/05/EN-MEDELLIN-SE RESPIRO-VIDA-CON-LA.HTML. FUENTE-B: HTTP://WWW.SKYSCRAPERCITY. COM/SHOWTHREAD.PHP? $\mathrm{T}=\mathbf{5 5 1 7 0 3}$

Fig. 8. Medellín day and Medellín night. Source-a: htTP://Par-Lando.blogspot.com/2011/05/enMEDELLIN-SE RESPIRO-VIDA-CON-LA.HTML. SOURCE-B: HTTP://WWW.SKYSCRAPERCITY.COM/SHOWTHREAD. PHP? $\mathrm{T}=\mathbf{5 5 1 7 0 3}$ 
Ciudad efímera en los eventos especiales (fig. 9 y 10), tales como Feria de las Flores y la Antioqueñidad; desfile de autos antiguos; cabalgata; las fiestas de fin de año con sus alumbrados navideños y la transformación del río Medellín con sus alegorías culturales, siendo anfitrión del turismo, las visitas, la vivencia y la recordación.

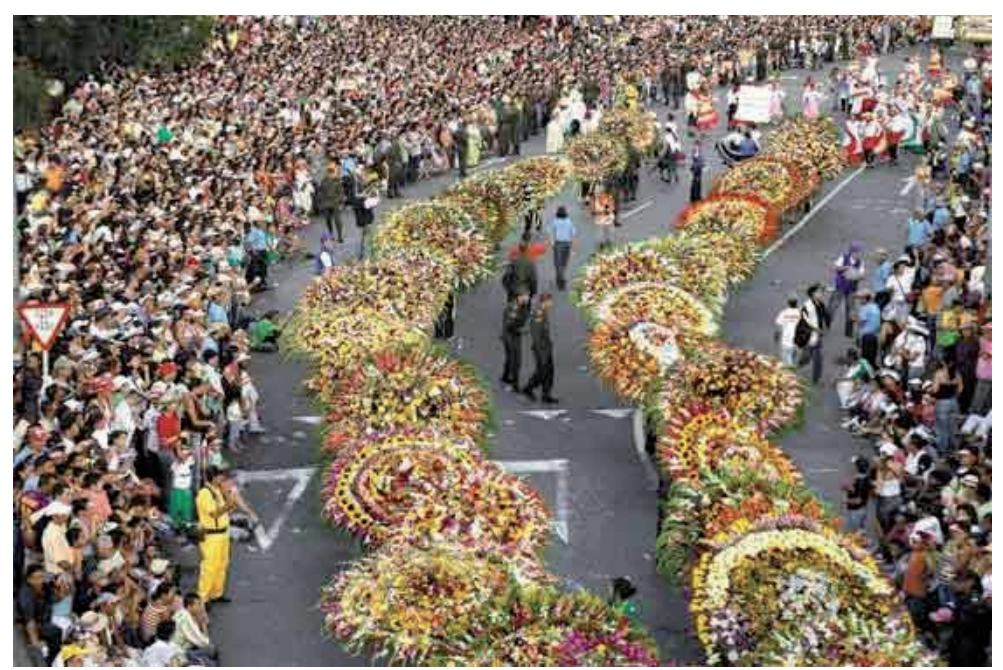

Fig. 9. Desfile de silleteros en la Feria de las Flores de Medellín.

FUENTE: HTTP://WWW.ELESPECTADOR.COM/FILES/IMG_ESPECIALES/68CA62FB6BA30657C7AE12B BA0461567.JPG

Fig. 9. Silleteros parade in the Feria de las Flores, Medellín.

SOURCE: HTTP://WWW.ELESPECTADOR.COM/FILES/IMG_ESPECIALES/68CA62 FB6BA30657C7 AE12B BA0461567.JPG

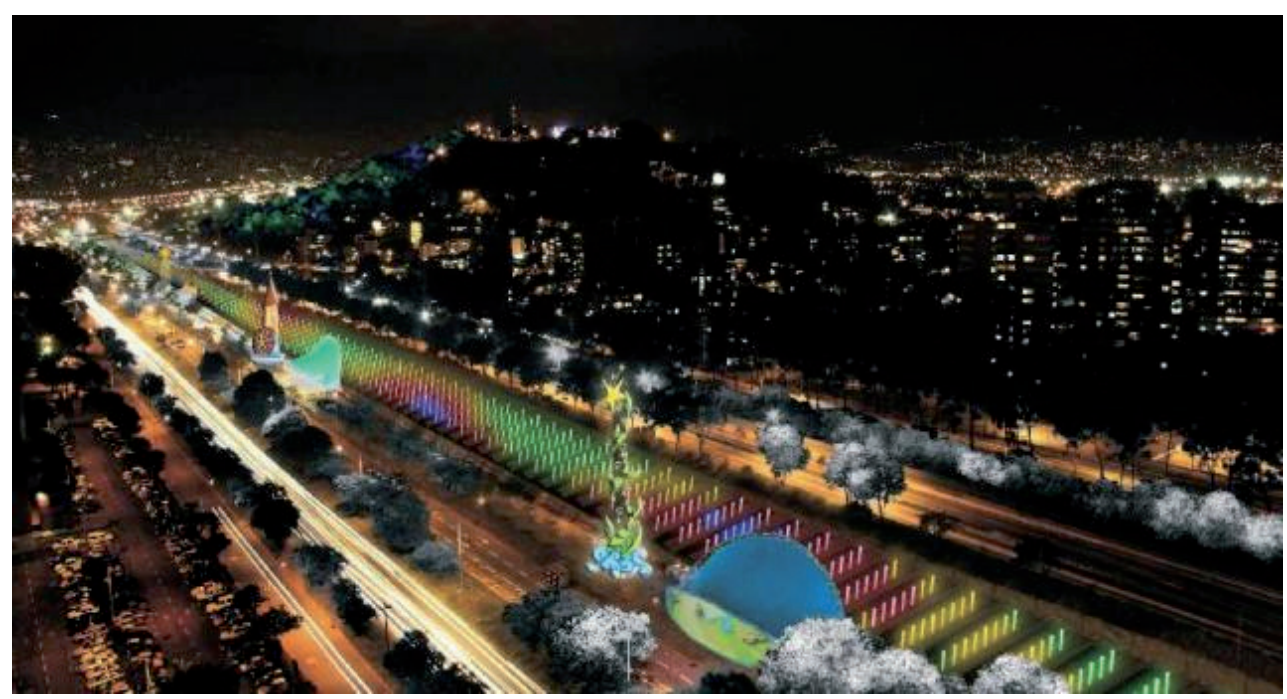

Fig. 10. Alumbrados decembrinos en el río Medellín. Fuente: htTp://discovercolombia.com/ CHRISTMAS-IN-MEDELLIN-COLOMBIA-LIGHTS-FILL-THE-CITY/

Fig. 10. Lighting decembrinas in the Medellín River. Source: httP://Discovercolombia.com/ CHRISTMAS-IN-MEDELLIN-COLOMBIA-LIGHTS-FILL-THE-CITY/ 
Con respecto al arte, Medellín también es constantemente una ciudad efímera, con muchos eventos artísticos llenos de emotividad, fuerza creativa e innovación, como por ejemplo el del colectivo artístico "El cuerpo habla", quienes plantearon como objetivo construir una semiótica del cuerpo de la contemporaneidad, a través del estudio y la práctica de una propuesta artística de cómo la performance conjuga el cuerpo de la ciudad y del arte y cómo esto permite crear una interpretación local del fenómeno dentro de la universidad y la urbe (Fig. 11).

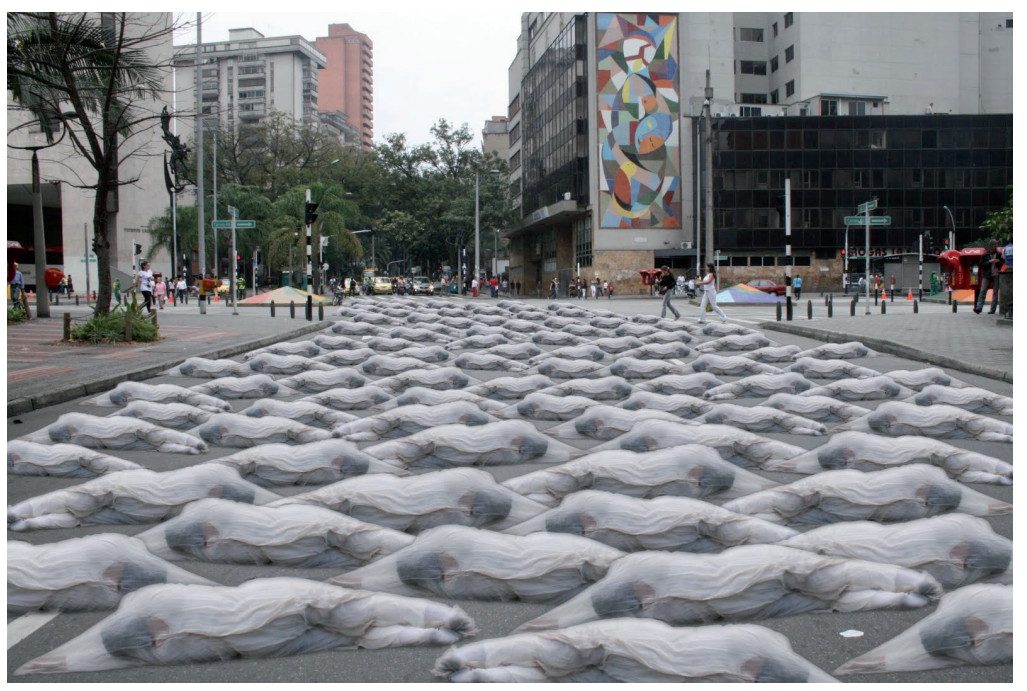

Fig. 11. Puesta en escena del colectivo "El cuerpo Habla". Performance en las calles de Medellín. Fuente: http://2.bp.blogspot.com/

Fig. 11. Staging "Body Talk". Performance in Streets of Medellín. SOURCE: http://2.bp.blogspot.com

Otra ciudad efímera corresponde a de color y alegría a sus habitantes. Esta es la experiencia The Color Run, una la ciudad efímera que por unos instantes se competencia mundial que se ha realizado convierten en diferente e irreconocible. en más de 50 ciudades del mundo, llenando

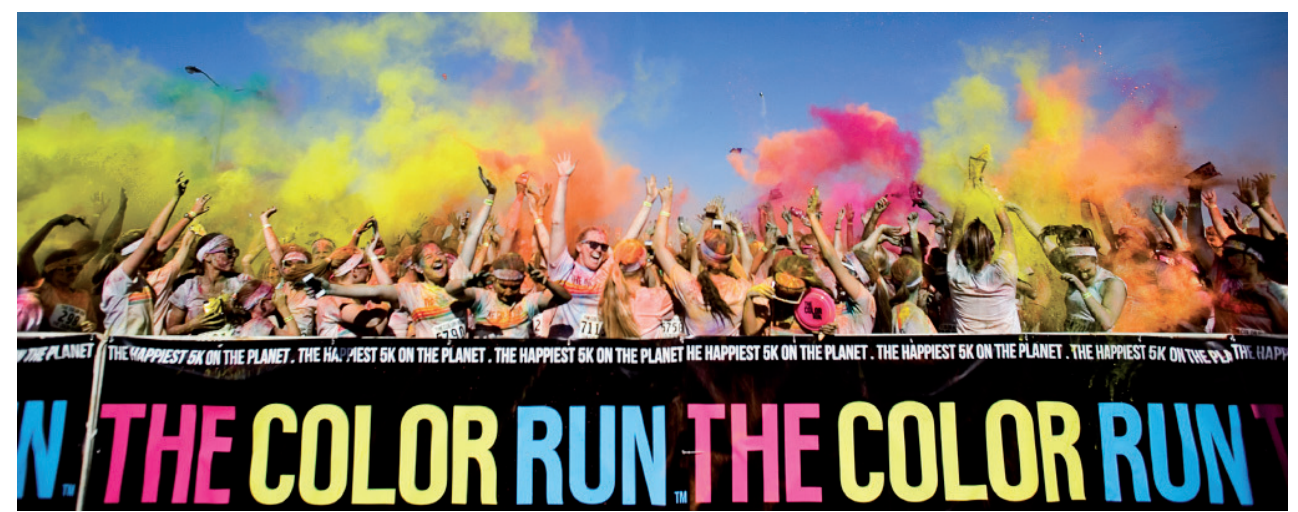

Fig. 12. "The Color Run", competencia mundial en Medellín. Septiembre 1 al 29 de 2013. FUENTE: http://steinerserves.org/

Fig. 12. "The Color Run", world competition in Medellín. 1 to 29 September 2013. SOURCE: $\underline{\text { http://steinerserves.org/ }}$ 


\section{Ciudad de nichos}

La ciudad es protectora y albergue, pero al mismo tiempo excluyente y discriminatoria en sus lugares, su gente y sus ambientes, en especial para la población que no se considera parte integrante de la ciudad, tales como pobladores en condiciones de indigencia, miseria y total abandono (Fig. 13).

Son estos pobladores los que dan lugar a otro tipo de ciudad, la ciudad de nichos. La ciudad contenedora de lugares donde se sientan protegidos, con acceso a sobras de comida, o donde estén alejados de las normas sociales para ser los más transitados por ellos, como el corredor del río, el centro, Niquitao, Barrio Triste, la avenida del Ferrocarril y el sector de Villanueva, entre otros.
La ciudad de nichos es aquella que se encuentra compuesta por pequeños sectores que han sido acondicionados por algunos pobladores para seguir perteneciendo a la ciudad, aunque no los acepten, aunque no haya un lugar específico para ellos, aunque no les pertenezca. Es el caso de los pobladores que encuentran su espacio en las grandes bocas de las alcantarillas que desembocan en el Río Medellín (Fig. 14). Allí habitan, viven y se sienten protegidos de un mal menor, pero que han convertido en mayor, que es el que constituye la discriminación humana, en comparación con el peligro que representa la subida de las aguas del río en temporada de lluvias.

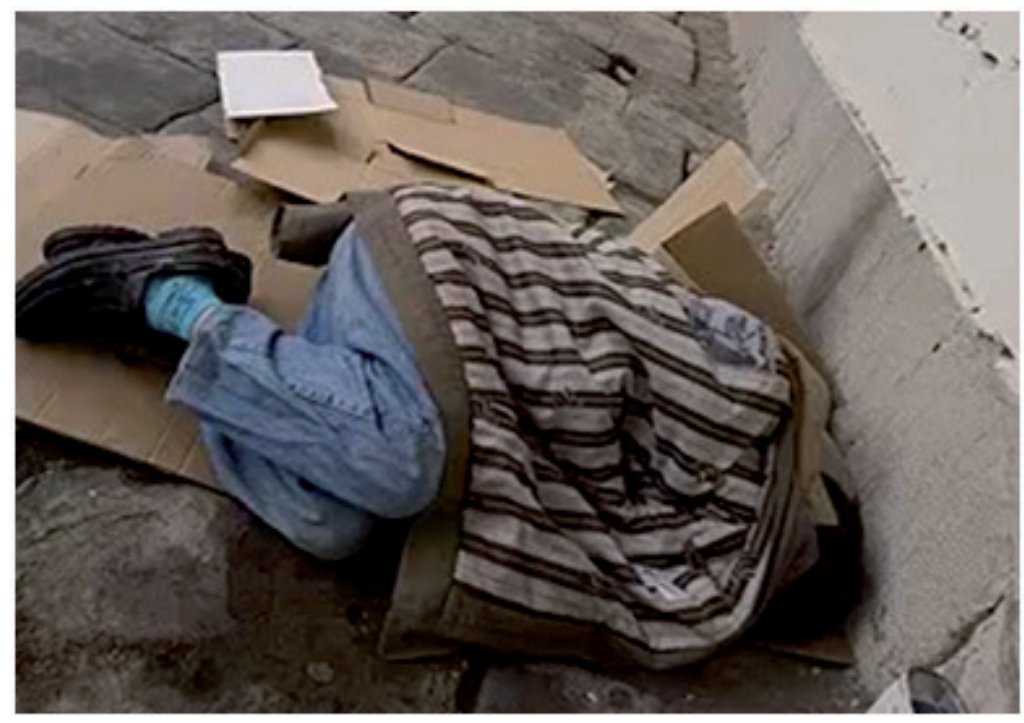

Fig. 13. Habitante de la Calle, centro de Medellín. Fuente: http://www.youtube.com.

Fig. 13. Homeless People in downtown Medellín. Source: http://www.youtube.com. 


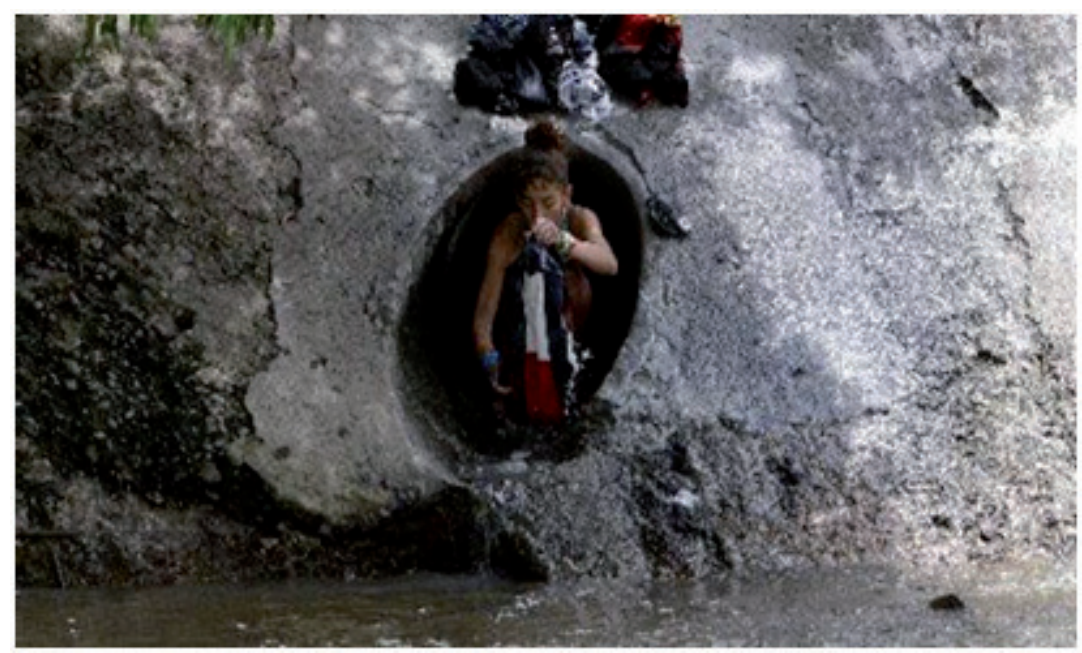

Fig. 14. Habitante de los ductos del río Medellín. Fuente: www.eltiempo.com.

Fig. 14. Person living in a duct which leads to the Medellín River. Source: www.eltiempo.com.

\section{Ciudad con maraña de redes}

Debido a la gran diversidad de actividades que permite en su permanencia, Medellín genera muchos tipos de pobladores así como pequeños núcleos urbanos que funcionan y se comportan como nodos de una gran red. Son pobladores agremiados reunidos por sus afinidades positivas o negativas, con la gran ilusión de adquirir mayor fuerza y poder social.

Estos núcleos urbanos, nodos o pobladores agremiados funcionan como entes independientes y a su vez como entes de una gran urbe o conglomerado. Es allí donde radica la exposición de su poder estructurado internamente.

El concepto de ciudad en red puede ser concebido en tres niveles diferentes. Un primer nivel macro es aquel en que la ciudad es un nodo a nivel global; la ciudad puede ser un poblado, metrópoli o simplemente un sector 0 área predominantemente activa en la aldea global. Las conexiones que se establecen en este nivel son preponderantemente centralizadas y poco convenientes hoy en día.

Un segundo nivel es aquel que se establece entre las ciudades a nivel metropolitano en donde las conexiones se caracterizan por ser descentralizadas y ampliamente difundidas. Un último nivel es aquel que se establece dentro de una misma ciudad en mayor proporción, donde cada punto de red está relacionado con varios a su vez de forma distribuida, conexiones denominadas redes urbanas (Fig. 15).

Es a este último nivel (red distribuida) al cual se hace referencia en este trabajo $\mathrm{y}$ en el que se reconocen redes diversas en la ciudad de Medellín, como la red de indigencia, la red de desplazados, la red de prostitución, la red de delincuencia, la red de comerciantes, la red de indígenas, la red de campesinos, la red de artistas urbanos, la red de afro-descendientes, entre otras. Cada una de estas redes o grupos humanos se forma por situaciones que la misma 
sociedad impone con sus manifestaciones, como la discriminación, el señalamiento, la desvalorización y el maltrato, razones que llevan a unos segmentos de la población a agremiarse con el fin de adquirir fortaleza en la unión.

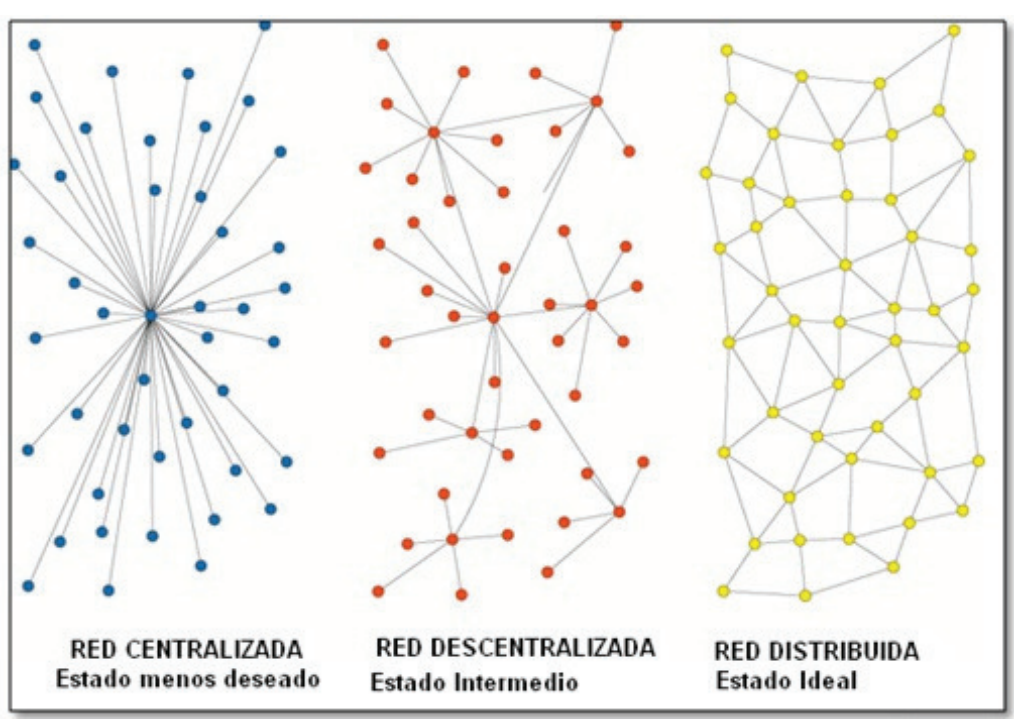

Fig. 15. Tipología de una red. Fuente: David de Ugarte (2011).

Fig. 15. Typology of A Network. Source: DaVId de Ugarte (2011).

\section{DISCUSIÓN}

Al finalizar este trabajo, la certeza alcanzada es que no conocemos la ciudad. Es difícil conocerla en estas condiciones de cambio permanente. Se puede coincidir con las disciplinas que estudian la ciudad, en decir que la ciudad es reconocida como paisaje urbano, un territorio en constante transformación a partir de sus modos de ser habitada, vivida y sobrevivida. Pero profundizar en apreciar cómo sus habitantes se transforman y a su vez transforman la ciudad, y cómo esta relación y constante metamorfosis aporta diversas características a la ciudad y sus habitantes, es complejo e imperceptible, aunque muy real. Ver de manera incomprensible y hasta artificiosa los espacios acondicionados para ser habitados según las necesidades de los diversos tipos de habitantes que la misma ciudad genera, apartándose del ideal estético pero reafirmando la función para la cual fue concebida la ciudad, requiere un compromiso social y cultural que comience por hacer efectiva nuestra función como ciudadano real.

Este circuito interminable de influencia e interferencia de ciudad dinámica, activa, viva $\mathrm{y}$ latente, es el que se tiene que reconocer como el contexto inmediato. No sirven miradas superfluas, no sirven apreciaciones ligeras. Aprender la ciudad que el hombre habita es una tarea de hoy, porque el conocimiento que realmente se posee de la ciudad, como espacio habitado, como paisaje urbano, es fragmentado, incompleto e imaginario. En este caso, el motor de la transformación del territorio está en la misma realidad, en la cotidianidad que forma la vida del hombre, la cual es tan repetitiva que hace ver todo conocido, pero al mismo tiempo sólo camufla otras realidades. 


\section{CONCLUSIONES}

A manera de conclusión se puede confirmar que la relación establecida entre los conceptos y los diferentes factores que favorecen las acciones de impermanencia, aparte de la afinidad que encuentra en su relación, ha dado como resultado una caracterización de la ciudad a partir de tipologías de la misma, que van implícitas en su función y que vienen generando una transformación del paisaje urbano de Medellín.

Se puede confirmar, de igual manera, que en Medellín se presentan de forma conjunta todas las tipologías expuestas e identificadas a partir de las relaciones conceptuales con lo efímero, lo nómada, las mutaciones, las hibridaciones, los nichos urbanos y las redes. Esto es posible en Medellín porque es una ciudad donde se presentan todos los factores que favorecen las acciones de impermanencia, de manera que su caracterización como ciudad se ve enriquecida por una transformación dinámica y permanente. Esto podría ser posible en cualquier otra ciudad del mundo, de manera concreta, con una tipología de ciudad en exclusiva o con varias, siendo un poco extraño que se presenten todas las tipologías al mismo tiempo, como sucede en Medellín, pero es muy posible que se trate de casos particulares.

Esta manera ecológica de ver la ciudad de Medellín y todas las ciudades, como paisajes urbanos, es un ejercicio que necesaria e inevitablemente impone una mirada profunda, reflexiva y comprensiva de la cotidianidad de sus habitantes. Pero, ver la ciudad está condicionado a la individualidad, por tanto, los cambios que hoy se reconocen de la ciudad ya han pasado por otros procesos de transformación, que actualmente permiten caracterizar en ella tipologías de ciudad y que en un futuro próximo ya habrán sido transformadas.

Indiscutiblemente, el paisaje urbano y todos los tipos de ciudad que el hombre genere en su necesidad de espacio habitable es paisaje en transformación, es paisaje latente, no siempre el más bello, pero sí representativo de la cultura, de estilos de vida, de formas de habitar con las necesidades, respuestas y caprichos del hombre, impresos en su imagen.

Es este paisaje el que se observa de la transformación de la ciudad, el que de manera tácita ordena el territorio, imprimiéndole características que lo hacen diferenciable, reconocible y característico. Porque el paisaje va adquiriendo la personalidad de sus habitantes a partir de los usos y el aprovechamiento a que lo expone el hombre. Sin embargo, la ciudad de Medellín ha pasado por situaciones adversas de tipo cultural, social y económico que la han marcado, al igual que la ha fortalecido la permanente transformación conceptual que se ha expuesto, porque con ello se fortalece su función de ciudad, pues son todas las evidencias, situaciones y tipologías descritas las que le permiten al habitante de Medellín escogerla, amarla y reconocerla como su espacio. Esta ciudad le permite al ciudadano encontrar su espacio, para acomodarse e identificarse y así habitarlo.

Finalmente se plantea la necesidad de avanzar en la discusión e indagación del vivir la ciudad con los ojos de los otros, aquellos que no conocemos y que no forman parte de nuestra cotidianidad, pero que también forman parte del grupo humano de habitantes de la ciudad, aquellos que paradójicamente en búsqueda de su comodidad transforman el paisaje urbano de Medellín. A partir de ello se concluye con las siguientes interrogantes:

¿Son conocidas las transformaciones que determinan y caracterizan la ciudad? ¿Es sabido cómo se genera el paisaje urbano en el que se vive, se percibe cotidianamente y que tal vez no se entiende ni reconoce? 


\section{REFERENCIAS}

ATRIBUTOS URBANOS, 2006. Un proyecto del Centro Andaluz de Arte Contemporáneo. Ciudad Nómada. Consultado en la dirección web: http:// www.atributosurbanos.es/terminos/ciudadnomada/

EL BANCO INTERAMERICANO DE DESARROLLO Y LA REDUCCIÓN DE LA POBREZA, 1998. Visión general. Parte 1: Trasfondo empírico y analítico de la pobreza y el crecimiento económico en América Latina y el Caribe. http:// idbdocs.iadb.org/wsdocs/getdocument. aspx?docnum $=1481846$.

BANCO MUNDIAL, 2015. Informe anual 2015. Trabajar para poner fin a la pobreza extrema y promover la prosperidad compartida. http://www.bancomundial.org/ es/about/annual-report/overview.

CENTRO NACIONAL DE MEMORIA HISTÓRICA, 2013. Informe general. Capítulo II: Los orígenes, las dinámicas y el crecimiento del conflicto armado. http:// centrodememoriahistorica.gov.co/

COMISIÓN ECONÓMICA PARA AMÉRICA LATINA Y EL CARIBE (CEPAL), 2002. Determinantes de la pobreza en Colombia: Años recientes. Naciones Unidas. http://www.cepal.org/es/ publicaciones/

DÁVILA, J., A. GILBERT, N. RUEDA \& P. BRAND, 2006. Suelo urbano y vivienda para la población de ingresos bajos. Estudios de caso: Bogotá-SoachaMosquera; Medellín y Área Metropolitana. Development Planning Unit, University College of London.
ECHEVERRI, A. \& F.M. ORSINI, 2010. Informalidad y Urbanismo Social en Medellín. Medellín: Medio ambiente, urbanismo y sociedad, 130-152. http:// www.catedramedellinbarcelona.org.

GUBER, R., 2001. La Etnografía. Método, campo y reflexividad. Enciclopedia Latinoamericana de Sociocultura y Comunicación. Grupo Editorial Norma. 147 págs.

MONTOYA, C. D., 2012. Paisaje natural en la ciudad. Reflexión sobre el significado del paisaje natural en las ciudades. Trabajo de Grado, Maestría en Diseño del Paisaje. Universidad Pontificia Bolivariana (UPB), Medellín, Colombia. Inédito.

NARANJO, G., 2001. Migración y cambio social. Scripta Nova. Revista Electrónica de Geografía y Ciencias Sociales No 94(1). http://www.ub.edu/geocrit/sn-94-37.htm.

PERGOLIS, J.C., 2000. Estética del desarraigo en la ciudad nómada. Revista de Estudios Sociales, 5: 108-114.

TRISMEGISTO, H., 2012. El Kybalión. Las Leyes Universales. Los siete principios básicos que rigen el universo. http://www. deeptrancenow.com/

DE UGARTE, D., 2011. Trilogía de las redes. Biblioteca de Las Indias. Libro electrónico: ISBN 978-9974-98-452-2. 